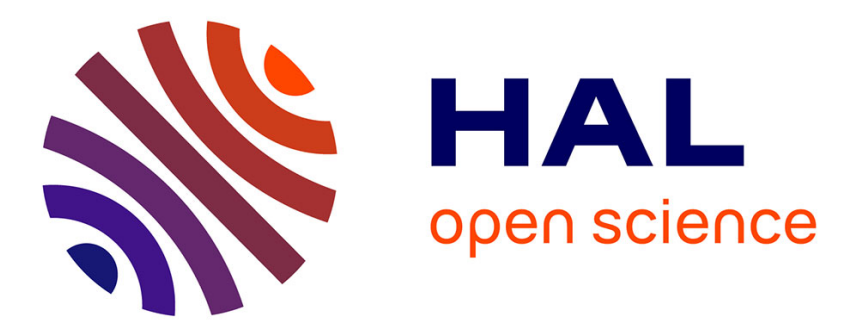

\title{
High Energy Excitation Transfer from Silicon Nanocrystals to Neodymium Ions in Silicon-Rich Oxide Film
}

\author{
Arthur Podhorodecki, Jan Misiewicz, Fabrice Gourbilleau, Julien Cardin, \\ Christian Dufour
}

\section{To cite this version:}

Arthur Podhorodecki, Jan Misiewicz, Fabrice Gourbilleau, Julien Cardin, Christian Dufour. High Energy Excitation Transfer from Silicon Nanocrystals to Neodymium Ions in Silicon-Rich Oxide Film. Electrochemical and Solid-State Letters, 2010, 13 (3), pp.K26-K28. 10.1149/1.3279688 . hal01139780

\author{
HAL Id: hal-01139780 \\ https://hal.science/hal-01139780
}

Submitted on 7 Apr 2015

HAL is a multi-disciplinary open access archive for the deposit and dissemination of scientific research documents, whether they are published or not. The documents may come from teaching and research institutions in France or abroad, or from public or private research centers.
L'archive ouverte pluridisciplinaire HAL, est destinée au dépôt et à la diffusion de documents scientifiques de niveau recherche, publiés ou non, émanant des établissements d'enseignement et de recherche français ou étrangers, des laboratoires publics ou privés. 


\title{
High Energy Excitation Transfer from Silicon Nanocrystals to Neodymium Ions in Silicon-Rich Oxide Film
}

\author{
A. Podhorodecki, ${ }^{\text {a,z }}$ J. Misiewicz, ${ }^{\mathrm{b}}$ F. Gourbilleau, ${ }^{\mathrm{b}}$ J. Cardin, ${ }^{\mathrm{b}}$ and C. Dufour ${ }^{\mathrm{b}}$ \\ ${ }^{a}$ Institute of Physics, Wroclaw University of Technology, 50-370 Wroclaw, Poland \\ ${ }^{b}$ Center of Research on Ions Materials and Photonics, UMR CNRS 6252, 14050 Caen Cedex 4, France
}

In this work, direct experimental evidence of the excitation energy transfer from silicon quantum dots (Si-QDs) to Nd ions has been given based on photoluminescence (PL) and PL excitation measurements in a wide spectral range. The indirect excitation of $\mathrm{Nd}$ ions by transfer from excited Si-QDs is possible and even more efficient at higher energy levels $\left({ }^{4} \mathrm{I}_{9 / 2} \rightarrow{ }^{4} \mathrm{D}_{3 / 2},{ }^{4} \mathrm{D}_{5 / 2}\right)$ than the indirect excitation reported up to now at lower energy $\left({ }^{4} \mathrm{I}_{9 / 2} \rightarrow{ }^{4} \mathrm{~F}_{3 / 2}-{ }^{4} \mathrm{~F}_{7 / 2}\right)$ levels.

(C) 2010 The Electrochemical Society. [DOI: 10.1149/1.3279688] All rights reserved.

Manuscript submitted October 28, 2009; revised manuscript received December 4, 2009. Published January 5, 2010.

The recent discovery of efficient luminescent emission from silicon nanoclusters ${ }^{1}$ and their sensitizing action toward rare-earth (RE) ions $^{2}$ has opened the field of important applications for integrated optoelectronic devices using the complementary metal oxide semiconductor technology. For example, in the fields of optical telecommunications, the erbium ion that emits at $1.54 \mu \mathrm{m}$ has become attractive because this wavelength corresponds to the minimum absorption of the optic silica fiber. For this reason, silica-based matrices co-doped with erbium ions and silicon quantum dots (Si-QDs) have been extensively investigated. ${ }^{3-9}$ However, up to now, among all the teams working on that domain, only one group has reported net gain in an Er-doped structure. ${ }^{10}$ One of the main reasons lies in the nature of the three-level electronic $4 \mathrm{f}$ structure of the $\mathrm{Er}^{3+}$ ions so that the de-excitation from ${ }^{4} \mathrm{I}_{13 / 2}$ to ${ }^{4} \mathrm{I}_{15 / 2}$ may lead to a reabsorption of the photon emitted by the neighboring $\mathrm{Er}^{3+}$ ions. Among the other RE ions that can benefit from the sensitizing effect of Si-QDs described by Kenyon et al., ${ }^{2} \mathrm{Nd}^{3+}$ offers the ${ }^{4} \mathrm{~F}_{13 / 2}{ }^{4} \mathrm{I}_{11 / 2}$ emission at about $1060 \mathrm{~nm}$, which corresponds to an operating mode based on four levels. The relaxation toward the fundamental state ${ }^{4} \mathrm{I}_{9 / 2}$ takes place by nonradiative de-excitation. Consequently, the signal emitted by the $\mathrm{Nd}^{3+}$ ions is not reabsorbed by another $\mathrm{Nd}^{3+}$ ion. This confers to the Nd-doped material the possibility of reaching a net gain. Therefore, such a Nd-doped system appears to be more favorable than its Er-doped counterpart for the achievement of a significant population inversion. It would consequently be the "preferred material" to obtain a net gain in structures containing Si nanoclusters even if the fiber absorption is higher at this emission wavelength than at $1.54 \mu \mathrm{m}$. The possible sensitizing role of Si-QDs toward $\mathrm{Nd}^{3+}$ in such a dielectric matrix has been reported so far by only a few studies. ${ }^{11-14}$ However, Seo et al. ${ }^{11}$ claimed that only films with $\mathrm{Si}$ content lower than 44 atom \% show significant $\mathrm{Nd}^{3+}$ luminescence because low $\mathrm{Si}$ excess is needed to precipitate small Si nanoclusters. Similar results were also reported by Franzo et al., ${ }^{3}$ who investigated Nd-implanted Si-rich silicon oxide (SRSO).

In this article, we discuss the indirect excitation of $\mathrm{Nd}^{3+}$ ions embedded in SRSO thin films produced by reactive magnetron cosputtering. We propose an excitation channel describing the energy transfer from the high energy levels of Si-QDs to the high energy levels of the $\mathrm{Nd}^{3+}$ ions.

Thin RE-doped layers were deposited by reactive magnetron cosputtering of a pure $\mathrm{SiO}_{2}$ target topped with $\mathrm{Nd}_{2} \mathrm{O}_{3}$ chips. The silicon excess in the layer was obtained through the monitoring of the hydrogen partial pressure mixed to the Ar plasma in the chamber. This reactive deposition approach was based on the ability of hydrogen to reduce the oxygen species originating from the sputtered $\mathrm{SiO}_{2}$ target. This allowed the control of $\mathrm{Si}$ incorporation in the growing thin films. ${ }^{15}$ The RE content was controlled through the number of the $\mathrm{Nd}_{2} \mathrm{O}_{3}$ chips placed on the $\mathrm{SiO}_{2}$ target. For this study,

${ }^{\text {z }}$ E-mail: artur.p.podhorodecki@pwr.wroc.pl
Si excess was kept constant at about 7 atom \%, while Nd concentration was fixed at 0.08 atom \%. These parameters have been chosen based on our previous investigation ${ }^{16}$ and have led to an optimal $\mathrm{Nd}$ emission intensity. The Nd-doped SRSO (Nd-SRSO) layers were deposited at a power density of $0.76 \mathrm{~W} \mathrm{~cm}^{-2}$ on $\left(\begin{array}{llll}1 & 0 & 0\end{array}\right)$ p-type $\mathrm{Si}$ wafers and were annealed at $1100^{\circ} \mathrm{C}$ for $1 \mathrm{~h}$ under a $\mathrm{N}_{2}$ flow.

Photoluminescence (PL) experiments have been obtained using a $266 \mathrm{~nm}$ excitation wavelength. The UV-visible spectral range has been detected by an HR4000 Ocean Optics spectrophotometer, while the near-IR visible emission has been collected by an InGaAs charge-coupled device camera after dispersing through a Triax 550 Jobin Yvon monochromator. For the total photoluminescence excitation (TPLE) measurements, a $450 \mathrm{~W}$ xenon lamp has been used as the excitation source. The configuration (Triax 180, Jobin Yvon monochromator and HR4000 Ocean Optics spectrophotometer) gives an averaged excitation flux lower than $\sim 10^{19}$ photons $/ \mathrm{s} \mathrm{cm}^{2}$ in the whole excitation range. The TPLE spectrum has been built from PL spectra corrected by the power wavelength dependency, integrated (hachured areas, Fig. 1) and plotted as a function of the excitation wavelength.

Figure 1a shows the PL spectrum obtained at $266 \mathrm{~nm}$ excitation wavelength for the SRSO matrix doped with $0.08 \%$ of $\mathrm{Nd}$ ions and annealed at $1100^{\circ} \mathrm{C}$. The emission band centered at $\sim 650 \mathrm{~nm}(1.9$ $\mathrm{eV})$ has been related to Si-QDs. Additionally, PL lines centered at 920, 1100, and $1400 \mathrm{~nm}$ correspond, respectively, to transitions originating from the ${ }^{4} \mathrm{~F}_{3 / 2}$ state to the ${ }^{4} \mathrm{I}_{9 / 2},{ }^{4} \mathrm{I}_{11 / 2}$, and ${ }^{4} \mathrm{I}_{13 / 2}$ levels of $\mathrm{Nd}$ ions. At nonresonant excitation, these strong Nd-related emissions suggest an efficient energy transfer from excited Si-QDs (or defect states) to Nd ions.

To further analyze this effect, TPLE spectra of Si-QDs and Nd ions recorded at $\sim 10^{19}$ photons $/ \mathrm{s} \mathrm{cm}^{2}$ are shown in Fig. $1 \mathrm{~b}$ and normalized to the maximum value. It can be observed that the strongest signal for both emission bands has been detected in the 250$450 \mathrm{~nm}$ range. We observed a similar shape of both excitation spectra obtained for Nd and Si-QDs, suggesting a common mechanism of the excitation for both elements. Additionally, except for the signal in the UV-vis range, there is no evidence of resonant excitation of $\mathrm{Nd}^{3+}$ ions or indirect excitation through Si-QDs at $488 \mathrm{~nm}$ at this low excitation flux.

Contrary to this result, the reference TPLE spectrum recorded for the Si-free Nd-doped commercial glass, using the same excitation flux shown in Fig. 1c, proves that the lack of resonant excitation bands for the SRSO-doped sample (Fig. 1b) is due to its very low excitation cross section (compared to indirect excitation) rather than due to the setup limitations. Such a result suggests that $(i)$ the direct excitation of $\mathrm{Nd}$ ions is not efficient for SRSO films, (ii) a high energy excitation followed by the energy transfer from Si-QDs to $\mathrm{Nd}^{3+}$ ions is observed, and (iii) this excitation mechanism is much more efficient than the indirect one reported up to now. ${ }^{11,14}$ This latter point is observed using the $488 \mathrm{~nm}$ argon laser excitation line, which allows us to populate lower energy states in the vicinity of 


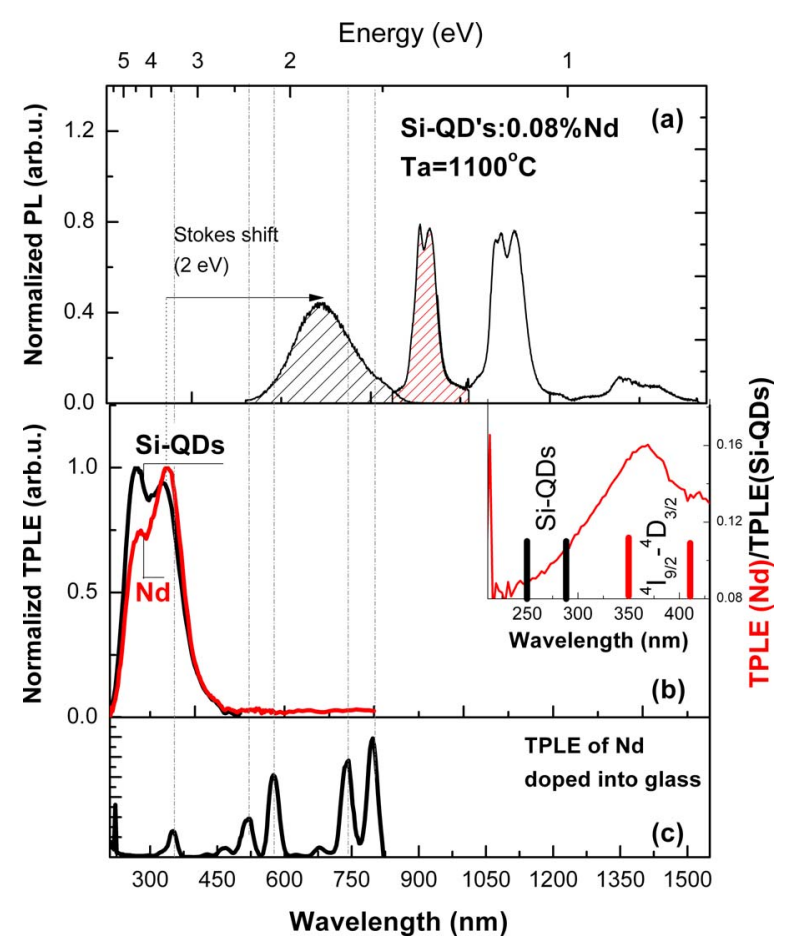

Figure 1. (Color online) (a) PL spectrum of SRSO:Nd sample annealed at $1100^{\circ} \mathrm{C}$ obtained at $266 \mathrm{~nm}$ excitation wavelength, (b) excitation spectra obtained for the emission band related to recombination in the vicinity of Si-QDs and for the emission band related to ${ }^{4} \mathrm{~F}_{3 / 2} \rightarrow{ }^{4} \mathrm{I}_{9 / 2}$ transition of $\mathrm{Nd}$ ion, and (c) reference excitation spectrum obtained for the emission band related to ${ }^{4} \mathrm{~F}_{3 / 2} \rightarrow{ }^{4} \mathrm{I}_{9 / 2}$ transition of $\mathrm{Nd}$ ion embedded inside the commercial glass matrix. Inset: Ratio of the excitation signal obtained for the $\mathrm{Nd}$ ion and for the Si-QD reflecting the excitation wavelength dependency of the energytransfer efficiency from Si-QDs to Nd ions.

Si-QDs from which the energy is transferred to the ${ }^{4} \mathrm{~F}_{3 / 2} \mathrm{Nd}$ level, but only at a much higher excitation flux.

To investigate the wavelength-dependent excitation mechanism, we focus on the $250-425 \mathrm{~nm}$ range. The observed emission intensity related to $\mathrm{Nd}$ ions is a combination of the probability of several processes: $\quad P_{\mathrm{PL}_{\mathrm{Nd}}}\left(E_{\mathrm{exc}}\right) \alpha P_{\mathrm{abs}_{\mathrm{Si}-\mathrm{Qds}}}\left(E_{\mathrm{exc}}\right) P_{\text {tran }}\left(E_{\mathrm{exc}}, E_{\mathrm{em}}\right) P_{\mathrm{em}_{\mathrm{Nd}}}\left(E_{\mathrm{em}}\right)$, where the first term describes the probability of Si-QD light absorption dependent on the excitation energy $E_{\text {exc }}$, the second term is the probability of the energy transfer from Si-QD to $\mathrm{Nd}$ ions dependent on the excitation and emission energies, $E_{\text {exc }}$ and $E_{\text {em }}$, and the last one is the probability of the $\mathrm{Nd}$ ion emission, which can be assumed to be excitation energy independent of indirect excitation via SiQDs. Thus, assuming that $P_{\mathrm{em}_{\mathrm{Nd}}}$ is constant, the ratio $\left(P_{\mathrm{PL}_{\mathrm{Nd}}} / P_{\mathrm{abs}_{\mathrm{Si}-\mathrm{Qds}}}\right)$ is a signature of the excitation wavelength dependency of the energy transfer between Si-QDs and Nd ions. This ratio is shown in the inset to Fig. 1b. The inset shows that the excitation process of the $\mathrm{Nd}$ ions is the most efficient at the $350 \mathrm{~nm}$ excitation wavelength, which is typical of the ${ }^{4} \mathrm{I}_{9 / 2} \rightarrow{ }^{4} \mathrm{D}_{3 / 2}$ and ${ }^{4} \mathrm{D}_{5 / 2}$ absorption bands of $\mathrm{Nd}$ ions and thus at an energy in which the resonant energy transfer takes place.

Such an energetically high process, which is more efficient than the energy transfer from the lower energy states, can be due to two facts. First, from the point of view of the silicon dot, the relaxation from the higher excited states is inhibited due to the discreteness of the states. ${ }^{17}$ Second, the relaxation process from the higher excited energy levels to the lowest ones can be strongly reduced due to the formation of charge-separated complexes as it has been evidenced for CdSe nanocrystals. ${ }^{8}$ Those two facts may increase the carrier's lifetime at higher energy levels, making energy transfer from these higher levels very efficient.

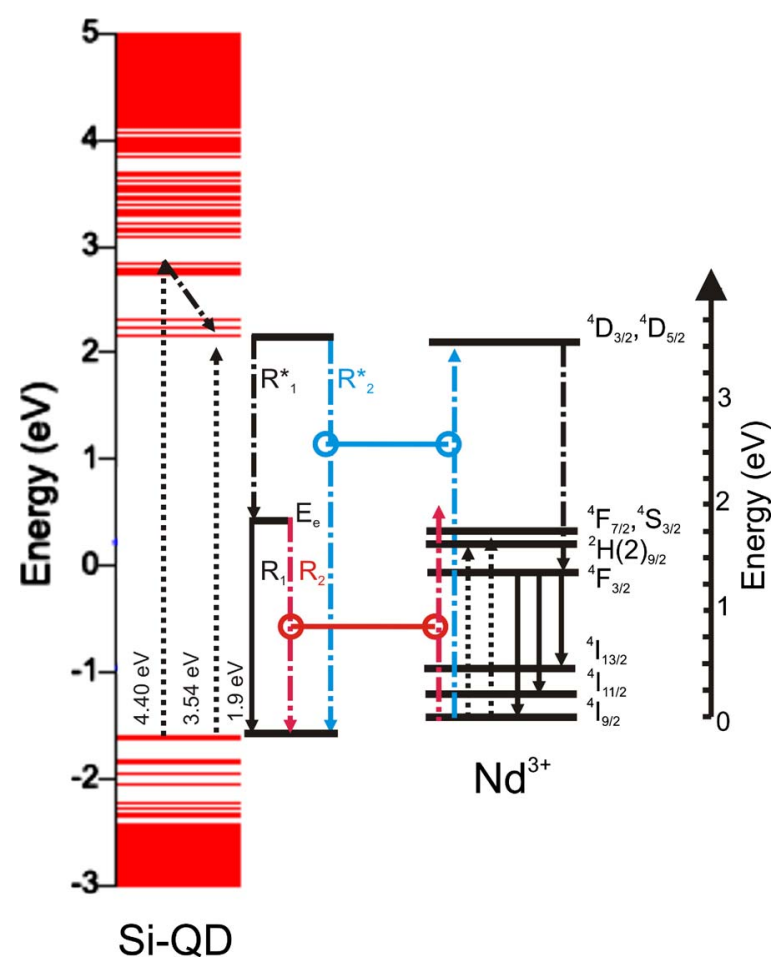

Figure 2. (Color online) Schematic presentation of possible excitation mechanisms of a silica matrix co-doped with $\mathrm{Nd}$ ions and Si-QDs. The energy levels for Si-QDs, with a size of $1.36 \mathrm{~nm}$, have been redrawn after Bulutay. ${ }^{21}$

This finding can have important applicative consequences because in most cases, researchers choose the RE ions based on the correspondence of their energy levels to the Si-QD bandgap $(\sim 1.5$ to $2.0 \mathrm{eV}$ ), evaluated from its emission band position. However, our result shows that the excitation energy can be transferred from the $\mathrm{Si}-\mathrm{QDs}$ to the Nd ions at much higher energies $(\sim 3$ to $5 \mathrm{eV})$ than usually assumed so that channels of excitation of the RE ions may open.

The last issue arising from Fig. 1b concerns the shape and the position of the excitation band related to Si-QDs, which is composed of two bands centered at $280 \mathrm{~nm}(4.40 \mathrm{eV})$ and $350 \mathrm{~nm}(3.54$ $\mathrm{eV})$. The double-peak nature and the sharp edge of the excitation band suggest the presence of well-crystallized nanocrystals, which can be expected at such high annealing temperatures. Moreover, such a high value of the Si-QD bandgap is characteristic of very small Si-QDs, with a diameter close to $2 \mathrm{~nm}$. For example, a very similar spectrum was obtained theoretically by Trani et al. ${ }^{19}$ for $\mathrm{Si}: \mathrm{H}$ nanocrystals with sizes close to $2 \mathrm{~nm}$, or by Wilcox et al. ${ }^{20}$ Similar absorption bands were also observed by Buluta ${ }^{21}$ for Si nanocrystals with a size of $1.36 \mathrm{~nm}$. The result obtained in his work has been schematically redrawn in Fig. 2.

These results enable us to provide a schematic representation of the energy levels of the Si-QD and Nd ions and a possible energytransfer process, which has been shown in Fig. 2. Thus, two main energy-transfer processes are possible in our system: the most efficient nonradiative energy transfer from higher energy levels of SiQDs $\left(R_{2}^{*}\right)$ and the weak nonradiative energy transfer from the lowest energy levels (most probably surface/defect states) described as $\left(R_{2}\right)$ and preceded by a carrier relaxation $\left(R_{1}^{*}\right)$ from higher energy levels (confined states of Si-QDs).

In summary, it has been shown that the excitation energy transfer from the Si-QDs to $\mathrm{Nd}$ ions is possible. Moreover, an excitation channel of $\mathrm{Nd}$ ions has been proposed and discussed. It has been shown that the excitation of $\mathrm{Nd}$ ions through the ${ }^{4} \mathrm{I}_{9 / 2}$ 
$\rightarrow{ }^{4} \mathrm{D}_{3 / 2},{ }^{4} \mathrm{D}_{5 / 2}$ transition from the higher energy levels of Si-QDs through the nonradiative energy-transfer process is very efficient and seems to be much more efficient than the excitation through the lower energy absorption transitions of $\mathrm{Nd}$ ion (i.e., ${ }^{4} \mathrm{I}_{9 / 2} \rightarrow{ }^{4} \mathrm{~F}_{5 / 2}$ ). This opens possibilities for sensitizing a wide range of RE ions and thus paves the way to promising photovoltaic or photonic applications.

\section{Acknowledgments}

The work was supported by the Polish Ministry of Education and Scientific Research through grant no. N515 074 31/3896 and by the Polonium project. Moreover, A.P. acknowledges the financial support from the Foundation for Polish Science under the START program. F.G., J.C., and C.D. thank the French National Agency (ANR), which supported this work through the Nanoscience and Nanotechnology program (DAPHNES project no. ANR-08-NANO005).

Wroclaw University of Technology assisted in meeting the publication costs of this article.

\section{References}

1. L. T. Canham, Appl. Phys. Lett., 57, 1046 (1990).

2. A. J. Kenyon, P. F. Trwoga, M. Federighi, and C. W. Pitt, J. Phys.: Condens. Matter, 6, L319 (1994).

3. G. Franzò, V. Vinciguerra, and F. Priolo, Appl. Phys. A: Mater. Sci. Process., 69, 3
(1999).

4. A. J. Kenyon, C. E. Chryssou, C. W. Pitt, T. Shimizu-Iwayama, D. E. Hole, N Sharma, and C. J. Humphreys, J. Appl. Phys., 91, 367 (2002).

5. D. Pacifici, G. Franzo, F. Priolo, F. Iacona, and L. Dal Negro, Phys. Rev. B, 67, 245301 (2003).

6. I. Izeddin, D. Timmerman, T. Gregorkiewicz, A. S. Moskalenko, A. A. Prokofiev, I. N. Yassievich, and M. Fujii, Phys. Rev. B, 78, 035327 (2008).

7. A. Podhorodecki, J. Misiewicz, J. Wójcik, E. Irvin, and P. Masher, J. Lumin., 121, 230 (2006).

8. F. Gourbilleau, C. Dufour, M. Levalois, J. Vicens, R. Rizk, C. Sada, F. Enrichi, and G. Battaglin, J. Appl. Phys., 94, 3869 (2003).

9. K. Imakita, M. Fujii, Y. Yamaguchi, and S. Hayashi, Phys. Rev. B, 71, 115440 (2005).

10. H. S. Han, S. Y. Seo, and J. H. Shin, Appl. Phys. Lett., 79, 4568 (2001).

11. S.-Y. Seo, M.-J. Kim, and J. Shin, Appl. Phys. Lett., 83, 2778 (2003).

12. K. Watanabe, H. Tamaoka, and M. Fujii, Physica E, 13, 1038 (2002).

13. A. N. MacDonald, A. Hryciw, F. Lenz, and A. Meldrum, Appl. Phys. Lett., 89, 173132 (2006).

14. D. Bréard, F. Gourbilleau, A. Belarouci, C. Dufour, and R. Rizk, J. Lumin., 121, 209 (2006).

15. C. Ternon, F. Gourbilleau, X. Portier, P. Voivenel, and C. Dufour, Thin Solid Films, 419, 5 (2002).

16. F. Gourbilleau, D. Bréard, C. Dufour, and R. Rizk, Opt. Mater. (Amsterdam, Neth.), 31, 479 (2009).

17. U. Bockelmann and G. Bastard, Phys. Rev. B, 42, 8947 (1990).

18. P. Guyot-Sionnest, M. Shim, C. Matranga, and M. Hines, Phys. Rev. B, 60, R2181 (1999).

19. F. Trani, G. Cantele, D. Ninno, and G. Iadonisi, Phys. Rev. B, 72, 075423 (2005).

20. J. P. Wilcoxon, G. A. Samara, and P. N. Provencio, Phys. Rev. B, 60, 2704 (1999).

21. C. Bulutay, Phys. Rev. B, 76, 205321 (2007). 